\title{
Distal 10q trisomy syndrome with unusual cardiac and pulmonary abnormalities
}

\author{
J Davies, A Jaffé, A Bush
}

\section{Department of Respiratory Paediatrics, Royal Brompton Hospital and National Heart and Lung Institute, Sydney Street, London SW3 6NP, UK \\ J Davies \\ A Jaffé \\ A Bush \\ Correspondence to: Dr Davies.}

Received 7 November 1996 Revised version accepted for publication 22 July 1997

\begin{abstract}
Since its description in 1965 , distal $10 \mathrm{q}$ trisomy has become recognised as a well defined, although rare syndrome, almost always the result of an unbalanced translocation. Typical features consist of psychomotor delay, a distinctive dysmorphic appearance, growth retardation, and, in some cases, cardiac, renal, and ocular abnormalities.

$(\mathcal{M}$ Med Genet 1998;35:72-74)
\end{abstract}

Keywords: distal 10q trisomy; cardiac abnormalities; pulmonary abnormalities

We report a child with partial trisomy $10 \mathrm{q}$, displaying many of the usual phenotypic abnormalities, who also had an unusual combination of cardiac and pulmonary abnormalities. These consisted of mild hypertrophic cardiomyopathy, ventricular septal defect, pulmonary stenosis (valvar and infundibular) with a moderate sized bronchial collateral supplying the right lung, absent right pulmonary veins, and a narrow, hypoplastic left main bronchus. This combination of anomalies presents an interesting management challenge and, to our knowledge, has not been described in children with this chromosomal abnormality.

\section{Case report}

The child was born to a primigravid, healthy mother. The paternal grandparents had seven miscarriages but there was no history of phenotypically abnormal children. The pregnancy had been uneventful, with no teratogenic exposure. Intrauterine growth retardation was noted and delivery was by caesarean section for fetal distress at 42 weeks' gestation. Birth weight was $2300 \mathrm{~g}$ (<3rd centile) and dysmorphic features included low set ears, epicanthic folds, hypertelorism, bilateral ptosis, a high forehead, broad nasal bridge, and a bow shaped mouth (fig 1). He had clinodactyly and a dermoid cyst in the middle of his forehead.

Chromosomal analysis showed an unbalanced translocation resulting in trisomy of the distal one third of the long arm of chromosome 10 (q24-26) (fig 2). A balanced translocation of that segment was found in his father between chromosomes 10 and 18 (fig 3), with breakpoints at $10 \mathrm{q} 24$ and $18 \mathrm{p} 11.31$ or 32 .

During his first two years, recurrent episodes of cardiac failure and respiratory tract infections with right upper lobe consolidation and collapse continued to be a problem. Normal investigations included immunoglobulin and IgG subclass levels, sweat electrolytes, neutrophil function studies, alpha-1-antitrypsin levels, viral and atypical serology, ciliary beat frequency, and cine barium swallow. Cincinnati view chest $x$ ray (penetrated for visualisation of airways) showed an extremely narrowed left main bronchus and some narrowing of the upper airways (fig 4).

Aged 5 years, he was continuing to show delay in his growth and development, but was walking well and had good comprehension. A CT chest scan showed early right sided bronchiectasis when investigated for haemoptysis associated with respiratory tract infections. There was absent perfusion and diffusely reduced ventilation on the right side on ventilation and perfusion scan. The left side appeared normal. Cardiac catheterisation showed absence of the right sided pulmonary veins. The left sided veins were normal, as were both pulmonary arteries. The right lung was also supplied by a moderate sized bronchial collateral. Valvar and infundibular stenosis of the right ventricular outflow tract was shown with suprasystemic right ventricular pressures (fig 5). At fibreoptic bronchoscopy, severe narrowing of the left main bronchus with complete cartilage rings was noted. In summary, virtually all the blood flow was to his left lung, whereas the main left bronchus was much narrower than the right.

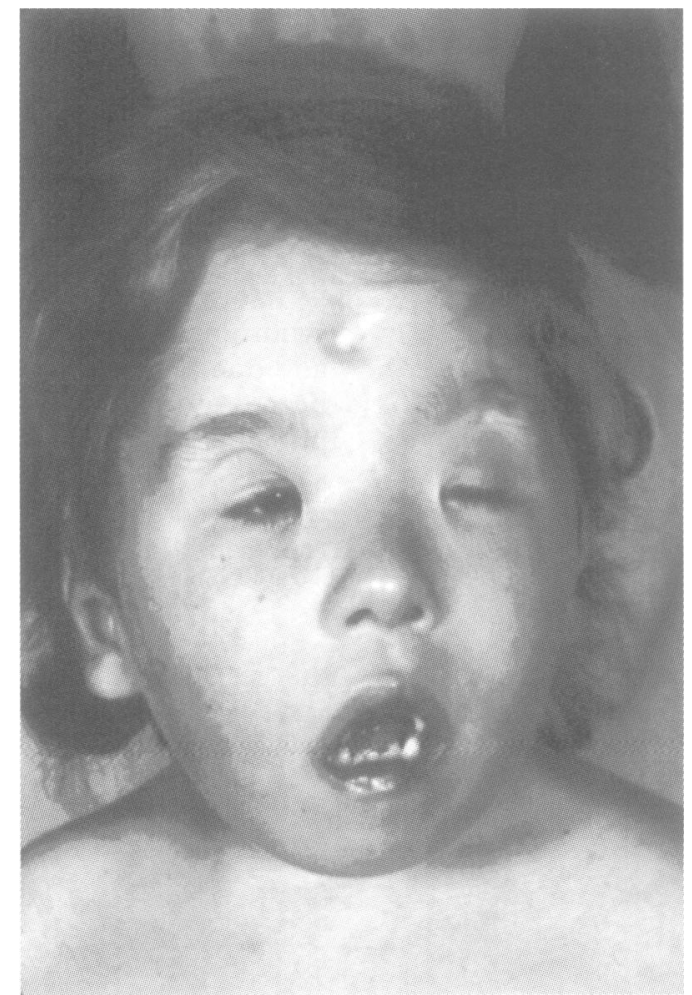

Figure 1 Typical facial features of distal 10q trisomy syndrome with forehead dermoid cyst removed. 


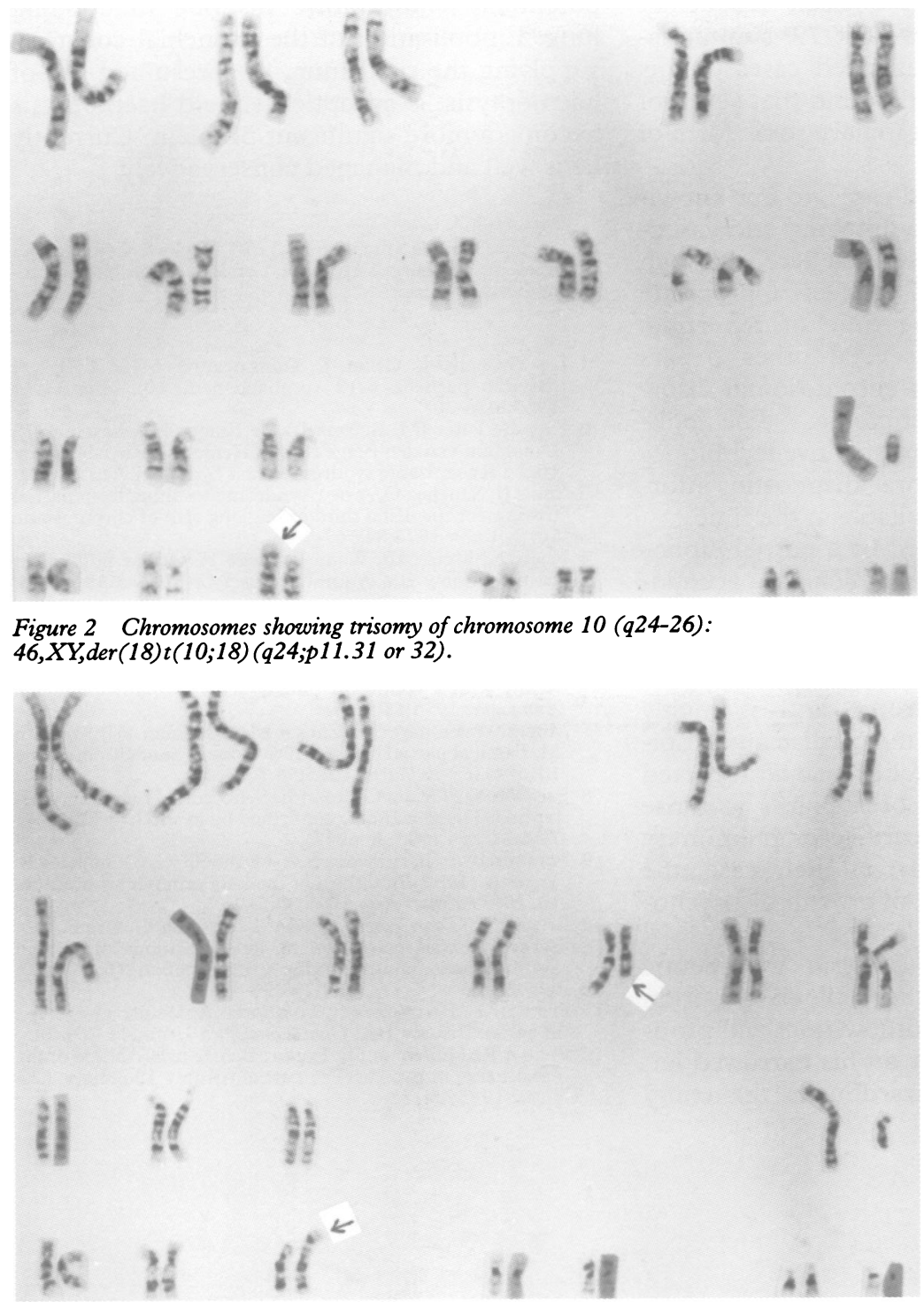

Figure 3 Paternal chromosomes showing balanced translocation between chromosomes 10 and 18: $46, X Y, t(10 ; 18)(q 24 ; p 11.31$ or 32$)$.

Following balloon dilatation of the right ventricular outflow tract, the child's respiratory symptoms have improved. Currently he still has recurrent chest infections, often with small haemoptyses, but without hypoxia or cardiac failure and not requiring admission to hospital.

\section{Discussion}

Partial trisomy of the long arm of chromosome 10 was first described in $1965^{1}$ and since then over 30 published reports have appeared of children with this disorder. ${ }^{2-10}$ The well recognised and defined type of trisomy of the long arm of chromosome 10 has been labelled the "distal 10q trisomy syndrome" to distinguish it from other forms of partial $10 \mathrm{q}$ trisomy. A recognisable phenotype has been suggested ${ }^{2}$ but critical attempts to correlate karyotype with phenotype are lacking. In this syndrome, of which our case is an example, the only common trisomic segment in these patients is the distal two chromosome bands 25 and 26 . Patients with the trisomic segment situated either proximally or in the middle of $10 \mathrm{q}$ have been less frequently described and do not rep-

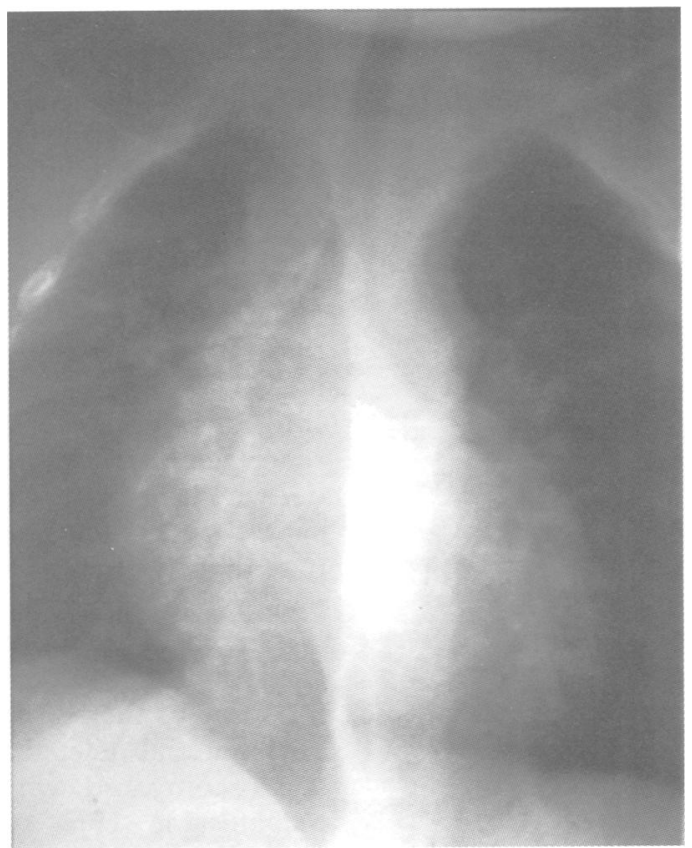

Figure 4 Chest $x$ ray (Cincinnati view) showing severe narrowing of main bronchus.

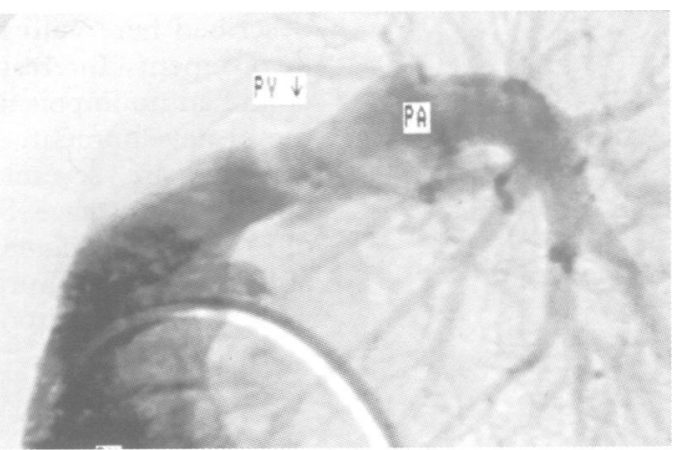

Figure 5 Cardiac catheter showing right ventricular outflow tract valvar and infundibular stenosis ( $P A=$ pulmonary artery, $P V=$ pulmonary valve).

Table 1 Dysmorphic features of distal 10q trisomy syndrome

\begin{tabular}{lll}
\hline Facial & Musculoskeletal & Other \\
\hline${ }^{\star}$ High/large forehead & Microcephaly & ${ }^{\star}$ Growth retardation \\
Round/flat face & ${ }^{\star}$ Hypotonia & ${ }^{\star}$ Psychomotor \\
${ }^{\star}$ Epicanthic folds & Joint laxity & ${ }^{\star}$ Cardiac abnormalities \\
${ }^{\star}$ Hypertelorism & ${ }^{\star}$ Clinodactyly & Ocular abnormalities \\
Fine eyebrows & Scoliosis & Renal abnormalities \\
Antimongoloid slants & Short neck & \\
${ }^{\star}$ Low set ears & & \\
Cleft palate & & \\
Retrognathia & & \\
^Flat nasal bridge & & \\
Short nose & & \\
${ }^{\star}$ Bow shaped mouth & & \\
\end{tabular}

^Features present in described case.

resent phenotypically distinct syndromes. Table 1 details the common features of the distal 10q trisomy syndrome.

Patients with trisomy 10q24 $\rightarrow$ qter tend to have more severe clinical manifestations such as heart or renal abnormalities. Ocular abnormalities are particularly well described and consist of hypertelorism, blepharophimosis, and micropthalmia as well as occasional fundal changes. ${ }^{411} 12$ Developmental delay to varying degrees is invariably present, and most cases also display somatic growth delay. 
Cardiac anomalies have been frequently reported. ${ }^{37}$ A publication in $1979^{2}$ summarising all the previously described cases of this chromosomal abnormality found that seven of 13 children were thought to have some form of congenital heart disease.

There are no published cases, to our knowledge, describing similar pulmonary and vascular anomalies to those described here, although this may be because of lack of appropriate investigative tools at the time of reporting. Interestingly, however, several other papers report children with this chromosomal disorder who have died of pneumonia. ${ }^{56}$ The application of more modern investigative techniques may have provided more diagnostic information had they been available at the time.

This case is complicated by a partial monosomy of chromosome $18 \mathrm{p}$ which may account for some of the features seen. The amount of $18 \mathrm{p}$ material deleted in this case is extremely small compared with those who have the recognisable $18 \mathrm{p}$ - syndrome and is highly unlikely to contribute to the cardiac and respiratory abnormalities. Forabosco et al reported a case with very similar breakpoints to those described here with no cardiac or pulmonary involvement. Interestingly, in their case, the child had no impairment of growth or psychomotor development.

There are several long term therapeutic options in this case. Further balloon dilatation of his right ventricular outflow tract will probably be required. Surgery on his narrowed left main bronchus is too hazardous as this could potentially compromise his one functioning lung. Embolisation of the bronchial collateral supplying the right lung, the presumed site of haemoptysis, is an option should haemoptysis become a more significant problem. Currently he is well and managed conservatively.

We would like to thank $\mathrm{Dr} J \mathrm{~W}$ Taylor, Cytogenetics Department, St George's Hospital, London, for his help in preparing this manuscript.

1 De Grouchy J, Canet J. Translocation 6-12, 13-15 et trisomie partielle 6-12 (probablement 10). Ann Genet trisomie partielle

2 Klep-de Pater JM, Bijlsma JB, de France HF, Leschot NJ, Duijndam-van den Berge M, van Hemel JO. Partial trisomy $10 \mathrm{q}$, a recognizable syndrome.Hum Genet 1979;46:29-40.

3 Yunis JJ, Sanchez O. A new syndrome resulting from partial trisomy for the distal third of the long arm of chromosome 10. F Pediatr 1974;84:567-70.

4 Neely $\mathrm{K}$, Mets MB, Wong P, Szego K. Ocular findings in partial trisomy 10q syndrome. Am $₹$ Ophthalmol 1988;106:

5 Taysi K, Yang V, Monaghan N, Beraha N. Partial trisomy $10 \mathrm{q}$ in three unrelated patients. Ann Genet 1983;26:79-85.

6 Kroyer S, Niebuhr E. Partial trisomy 10q occurring in a family with a reciprocal translocation $t(10 ; 18)$ (q25;q23). Ann Genet 1975;18:50-5.

7 Moreno-Fuenmayor H, Zackai EH, Mellman WJ, Aronson M. Familial partial trisomy of the long arm of chromosome 10(q24-26). Pediatrics 1975;56:756-61.

8 Briscioli V, Floridia G, Rossi E, Selicorni A, Lalatta F, ZufBriscioli V, Floridia G, Rossi E, Selicorni A, Lalatta F, Zuff Med Genet 1993;30:601-3.

9 Forabosco A, Bernasconi S, Giovannelli G, Dutrillaux B. Trisomy of the distal third of the long arm of chromosome 10. Helv Paediatr Acta 1975;30:289-95.

10 Brusnicky J, Van Heerden KMM, De Jong G, Cronjé AS. Severe mental retardation in six generations of a large South African family carrying a translocation $\mathrm{t}(6 ; 10)(\mathrm{q} 27$; q25.2). F Med Genet 1986;23:435-45.

11 Prosperi L, Bernasconi S, Forabosco A. Ocular phenotype in partial trisomy 10q. Ophthalmologica 1977;175:269-74.

12 Pfeiffer RA, Jünemann B, Lorenz B, Sieber E. Aplasia of the optic nerve in two cases of partial trisomy 10q24-ter. Clin Gentic nerve in two cas;
Ge: $183-7$. 